\title{
Influence of the Quality of Endodontic Treatment and Coronal Restorations on the Prevalence of Apical Periodontitis in a Turkish Cypriot Population
}

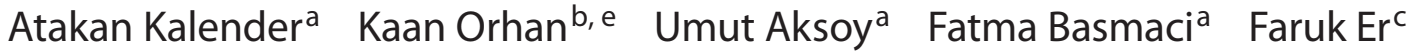 \\ Aslıhan Alankus ${ }^{d}$ \\ Departments of a Endodontics and ${ }^{b}$ Dentomaxillofacial Radiology, Faculty of Dentistry, Near East University, \\ and Departments of ${ }^{\mathrm{C}}$ Restorative Dentistry and ${ }^{\mathrm{d}}$ Pediatric Dentistry, Faculty of Dentistry, Near East University,

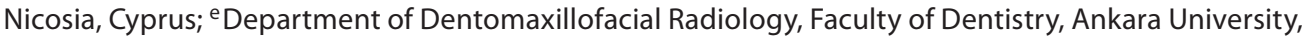 \\ Ankara, Turkey
}

\section{Key Words}

Apical peridontitis · Endodontic treatment $\cdot$ Radiographic evaluation

\begin{abstract}
Objectives: The aim of this study was to assess the prevalence of periapical lesions in root canal-treated teeth in a Turkish Cypriote population and to investigate the influence of the quality of root canal fillings and coronal restorations on the prevalence of periapical lesions. Subjects and Methods: The sample for this cross-sectional study consisted of 1,006 adult patients seeking routine dental care. Patients who had received dental care in the last 2 years were excluded. Radiographs of 2,200 root canal-treated teeth were evaluated. The teeth were grouped according to the radiographic quality of the root canal filling and the coronal restoration. Periapical status was assessed using periapical index (PAI) scores. Results: Of the 2,200 root canal-treated teeth, 1,364 (62\%) had apical periodontitis as compared with 1,364 (5.5\%) of the total sample. Root-filled teeth classified as adequately treated had apical periodontitis in 223 (26.6\%) cases compared with $1,192(87.7 \%)$ in teeth classified as inadequately root filled. PAI 1 scores of adequate root canal treatment
\end{abstract}

\section{KARGER}

E-Mail karger@karger.ch www.karger.com/mpp

\section{(C) 2012 S. Karger AG, Basel} 1011-7571/13/0222-0173\$38.00/0

Karcer

Open access

This is an Open Access article licensed under the terms of the Creative Commons Attribution- NonCommercial-NoDerivs 3.0 License (www.karger.com/OA-license), applicable to the online version of the article only. Distribution for non-commercial purposes only. were significantly higher than in inadequate root canal treatment, regardless of the quality or presence of coronal restorations $(p<0.01)$. Conclusion: Our findings showed a high prevalence of periapical pathology with or without endodontic treatment and poor technical standard of both root fillings and coronal restorations of root-treated teeth. Hence, we suggest the need for better education for dental health providers so that they can perform better root canal treatments and coronal restorations.

Copyright $\odot 2012$ S. Karger AG, Basel

\section{Introduction}

As the high prevalence of apical periodontitis of endodontic origin raises an important public health problem in many countries, numerous epidemiological studies have been designed to investigate the prevalence and outcome of root canal treatments and the periapical status of root-treated teeth [1-4]. It is generally accepted that the outcome of endodontic treatment is positively correlated with the technical quality of the root filling, which is expected to provide a hermetic seal against bacterial ingress [1]. However, it has been suggested that the quality of the 
coronal restoration may also have an impact on the periapical health of root-filled teeth $[2,3]$.

The assessment of endodontic treatment quality requires clinical as well as radiological follow-ups at regular intervals. The absence of clinical symptoms and a radiograph with an intact periodontal ligament space in the apical region are indications of healing, while the persistence of apical periodontitis is a sign of a continued disease state. If the radiolucency decreases overtime, the pathosis is also considered to be 'healing' [5].

Failure of a root canal treatment is usually characterized by persistence of apical periodontitis around the apex of the tooth [6,7]. A number of factors have been identified such as intra-radicular infections persisting in the apical part of the root canal or the failure of endodontic treatment and/or coronal restorations [8].

It has been reported that apical periodontitis is a widespread disease among the adult populations of a number of countries in Europe, North America, and Japan, and its prevalence (4-9\%) increases significantly when considering only root-filled teeth, ranging then from 20 to $65 \%$ [9-12]. Numerous epidemiological studies [9-16] designed to evaluate dental health have reported a high prevalence of apical periodontitis of endodontic origin, which raises an important public health problem in many countries concerning the medical, economic, and ethical repercussions. As the quality of root canal fillings and coronal restorations and their association with periapical status in a Cypriot subpopulation have not been studied previously, this information is crucial to assess the effectiveness of dental care.

Hence, the objective of the study was to determine the prevalence of periapical lesions in root canal-treated teeth in a Turkish Cypriot subpopulation and to investigate the influence of the quality of root canal fillings on the prevalence of periapical lesions.

\section{Subjects and Methods}

The sample for this cross-sectional study consisted of 1,006 adult patients (age range $18-50$ years) seeking routine dental care at the Near East University, Nicosia, Cyprus. All proposed subjects agreed to participate in the study and all of the patients gave written informed consent. For enrollment into the study, the patient's dental record had to contain a panoramic radiograph with supplemental periapical radiographs. Periapical radiographs were only used when panoramic radiographs showed poor image quality particularly in the upper and lower anterior region. All periapical radiographs were taken using the paralleling technique. All radiographs were taken and processed at the same radiology center in 2008-2010.
The OPGs were taken with a Planmeca PM 2002 CC Proline (Planmeca, Helsinki, Finland) set as a magnification of 1.25 as recommended by the manufacturer. All radiographs were acquired in the natural head position with stabilization via head rods. The exposure settings were $66-70 \mathrm{kVp}$ and $8-10 \mathrm{~mA}$ for $12 \mathrm{~s}$ per exposure. The digital images were stored in a computer database with the manufacture's software (Dimaxis pro, version 4.0.5; Planmeca).

All radiographs' magnification was corrected with the calibration process. The films were calibrated by digitizing two points on the ruler within the digital image using the manufacturer's software (Dimaxis pro, version 4.0.5; Planmeca). Variables were automatically generated by the program once a set landmark had been digitized. All evaluations were performed on a 21.3-inch flat panel color active matrix TFT medical display (Nio Color 3MP; Barco, France) with a resolution of $2,048 \times 1,536$ at $76 \mathrm{~Hz}$ and a $0.2115-\mathrm{mm}$ dot pitch operated at 10 bits. The examiners also were permitted to use enhancements and orientation tools such as magnification, brightness, and contrast to improve visualization of the landmarks.

In total, the radiographs of 2,200 root-filled teeth were evaluated. The teeth were grouped according to the radiographic quality of the root canal filling and the coronal restoration. The criteria used for the examination were slightly modified from those described by De Moor et al. [10] and Gündüz et al. [15] as follows.

\section{Quality of the Root Filling}

Adequate: All canals were obturated. There was no void present. The end of the root canal fillings was $0-2 \mathrm{~mm}$ short of the radiographic apex. Inadequate: The ends of the root canal fillings were more than $2 \mathrm{~mm}$ short of the radiographic apex or grossly overfilled. Root canal fillings had voids, inadequate density, unfilled canals, and/or poor condensation.

\section{Coronal Restoration}

Adequate: Intact restoration with good margin adaptation and no signs of recurrent caries. Inadequate: Restoration with overhangs, open margins, or recurrent caries, or no restoration at all.

\section{Periapical Status}

Apical status was assessed using the periapical index (PAI) proposed by Orstavik et al. [16] who scored the apical area of the radiographic images as follows: normal periapical structures, small changes in bone structure, changes in bone structure with little mineral loss, periodontitis with a well-defined radiolucent area, and severe periodontitis with exacerbating features.

A score of PAI 1 was defined as a healthy periapical region, indicating a normal width of the permanent ligament space and normal appearance of the surrounding bone. All other PAI scores were evaluated as apical periodontitis.

An endodontic consultant (A.K.) and a dental radiologist evaluated and interpreted the images independently without knowing the prevailing clinical conditions of the patients. Both examiners were calibrated. For this purpose, 20 OPGs not included in the survey were used to calibrate the examiners. As a part of the calibration phase, the study methodology was also explained to the examiners. Multi-rooted teeth were classified according to the root with the most severe score.

When disagreement occurred, a third observer, a dental radiologist (K.O.) with 14 years of clinical experience, was asked to 
evaluate the image. Besides, when the assessments were all different, the final diagnosis was obtained by repeating the evaluations and discussion between all examiners.

The inter-examiner agreement was determined by calculating Cohen's kappa [17], which turned out to be 0.82 , indicating a very good agreement between examiners. SPSS software was used for statistical analysis (SPSS Inc., Chicago, Ill., USA). Differences between the groups were examined using the $\chi^{2}$ test. $p<0.05$ was considered statistically significant.

\section{Results}

The total number of teeth examined was 24,730 , of which 2,200 (8.9\%) had root fillings; 1,360 (61.8\%) were deemed inadequate (table 1). Also 1,364 (62\%) of the rootfilled teeth had apical periodontitis as compared with $5.5 \%$ of the total sample. When the root-filled teeth were removed from the sample, apical periodontitis was observed in 370 non-root-filled teeth, with a percentage of $1.5 \%$ (table 1). One thousand four hundred thirty (65\%) of the root-filled teeth were in the maxilla. The incidence of disease in root-filled teeth was higher in the mandible (31\%) than in the maxilla (24.1\%). Root-filled maxillary molars (577; 77\%), mandibular premolars (123; 41\%), and mandibular incisors $(71 ; 34.1 \%)$ were particularly associated with apical periodontitis.

Root-filled teeth classified as adequately treated had apical periodontitis in $23(26.6 \%)$ cases compared with $1,192(87.7 \%)$ in teeth classed as inadequately root filled. The quality of the endodontic treatment seemed to exert a greater impact on the outcome than the quality of the coronal restoration. Moreover, the number of teeth with adequate root canal fillings and inadequate coronal restorations which got a PAI 1 score was significantly higher than the number of teeth with inadequate root canal fillings and adequate coronal restorations (table 2). In general, the success rates of adequate root canal treatment were significantly higher than those of inadequate root canal treatment, regardless of the quality or presence of the coronal restoration $(\mathrm{p}<0.01)$.

The type of coronal restoration was also recorded, where a root filling was present. Seven hundred seventy (35\%) of the root filled teeth were most commonly restored with materials of radio-opacity similar to composite glass ionomer or zinc oxide and eugenol cement. Post and core crowns were present in $72(26 \%)$ of the rootfilled teeth. Amalgam restorations and crowns were found in 462 (21\%) and 242 (11\%) of the root-filled teeth, respectively. One hundred fifty-four $(7 \%)$ of the rootfilled teeth were not restored and showed the highest in-
Table 1. Prevalence of root-filled teeth and teeth with apical periodontitis

\begin{tabular}{lc}
\hline Variables & $\begin{array}{l}\text { Teeth } \\
\mathrm{n}(\%)\end{array}$ \\
\hline $\begin{array}{l}\text { Subjects examined (423 males; 583 females) } \\
\text { Subjects with root-filled teeth }\end{array}$ & 1,006 \\
$\begin{array}{l}\text { Subjects with apical periodontitis } \\
\text { Teeth present in the sample }\end{array}$ & $642(64.0)$ \\
$\quad$ (male 11,104; female 13,626) & 24,730 \\
$\begin{array}{l}\text { Root-filled teeth } \\
\text { Root-filled teeth with apical periodontitis }\end{array}$ & $2,200(8.9)$ \\
$\begin{array}{l}\text { Inadequate root-filled teeth } \\
\text { Root-filled teeth with apical periodontitis }\end{array}$ & $1,364(5.5)$ \\
Apical periodontitis with and without & $1,360(61.8)$ \\
$\quad$ endodontic treatment & $1,364(62.0)$ \\
Apical periodontitis without endodontic treatment & $1,734(7.0)$ \\
Apical periodontitis with endodontic treatment & $370(21.3)$ \\
& $1,364(78.7)$ \\
\hline
\end{tabular}

Table 2. Periapical status of root-filled teeth as related to the quality of the coronal restoration combined with the quality of the endodontic treatment

\begin{tabular}{lll}
\hline $\begin{array}{l}\text { Endodontic } \\
\text { treatment }\end{array}$ & $\begin{array}{l}\text { Coronal } \\
\text { restoration }\end{array}$ & $\begin{array}{l}\text { PAI 1 } \\
\mathrm{n}(\%)\end{array}$ \\
\hline Adequate & Adequate & $508 / 658(77.2)$ \\
Adequate & Inadequate & $171 / 264(64.7)$ \\
Inadequate & Adequate & $116 / 502(23.1)$ \\
Inadequate & Inadequate & $41 / 776(5.2)$ \\
\hline
\end{tabular}

cidence of apical periodontitis (84.4\%), while $63 \%$ of the root-filled teeth with a crown had apical periodontitis. Teeth with post and core restorations had a $57.6 \%$ incidence of apical periodontitis (table 3).

\section{Discussion}

The reproducibility of the observer (Cohen's $\kappa=0.82$ ) was in very good agreement, probably because of prior calibration. The radiographic evaluation regarding the prevalence of apical paradontitis in this study revealed that $8.9 \%$ of teeth had root fillings and $61.8 \%$ were deemed inadequate. Moreover, $62 \%$ of the root-filled teeth had apical periodontitis as compared to $5.5 \%$ of the total sample, which is within the range of $2-9 \%$ as in previous studies $[9,12,18,19]$. The prevalence of root-filled teeth in the Turkish Cypriot population was lower than report- 
Table 3. Prevalence of apical periodontitis in root-filled teeth according to the type of coronal restoration

\begin{tabular}{llll}
\hline $\begin{array}{l}\text { Restoration } \\
\text { type }\end{array}$ & $\begin{array}{l}\text { Root-filled } \\
\text { teeth } \\
\text { restoration, } \\
\mathrm{n}(\%)\end{array}$ & $\begin{array}{l}\text { Root-filled teeth } \\
\text { with apical } \\
\text { periodontitis } \\
\text { restoration, } \mathrm{n}(\%)\end{array}$ & $\begin{array}{l}\text { Root-filled teeth } \\
\text { without apical } \\
\text { periodontitis } \\
\text { restoration, n (\%) }\end{array}$ \\
\hline Amalgam & $462(21)$ & $302(65.3)$ & $160(34.7)$ \\
Composite & $770(35)$ & $537(69.7)$ & $233(30.3)$ \\
Crown & $242(11)$ & $152(62.8)$ & $90(37.2)$ \\
Post & $572(26)$ & $329(57.6)$ & $243(42.4)$ \\
Unrestored & $154(7)$ & $130(84.4)$ & $24(15.6)$ \\
\hline Total & $2,200(100)$ & $1,364(62)$ & $836(38)$ \\
\hline
\end{tabular}

ed in previous studies $[2,20,21]$, but there were other studies [6,22] with findings similar to ours. Kirkevang et al. [23] found the prevalence to be $4.8 \%$, while Gencoglu et al. [6] indicated a prevalence of $9.39 \%$. On the contrary, Dugas et al. [1] investigated two populations and indicated prevalences of 26 and 39\%, respectively. Similarly, Molander et al. [21] found a prevalence of $63 \%$ which is higher than our results. It should also be stated that criteria for apical periodontitis vary among studies $[12,22]$. In recent years, most of the studies on the prevalence of AP have used this index scoring to assess periapical status, so the results of this study can be more appropriately compared with them $[1,22]$. Variations in health care services and socioeconomic factors in the various countries may contribute to these differences. This study revealed that $62 \%$ of the root canal-treated teeth exhibited apical periodontitis lesions, a figure within the range reported by several epidemiologic studies from different countries as follows: Belgium, 40\% [10]; Brazil, 51\% [24]; Canada, 44 and 51\% [1]; Denmark, 52\% [23]; Spain, 64.5\% [25], and Turkey, 67.9\% [15]. A high prevalence of apical periodontitis was mostly related to the high prevalence of teeth with inadequate endodontic treatment, which is in agreement with virtually all of the previous studies from different geographic locations $[7,15,23,25]$.

In the present study, root-filled teeth that had no restoration within the access cavity had the highest incidence of apical periodontitis. Root-filled teeth with amalgam restorations showed less apical pathosis than did crowned teeth, which is similar to the results of Buckley and Spangberg [11] (a study involving an American subpopulation) and Loftus et al. [26] (a study in an Irish population). It is speculated that post placement represents a significant hazard for the root canal system, either through risk of perforation or disturbance of the apical seal. Only $15.9 \%$ of post-restored root-filled teeth had apical periodontitis in this study compared with $40.0 \%$ with a non-post-retained crown restoration. Whereas Boucher et al. [19] reported an increased prevalence of apical periodontitis for teeth restored with posts [19], several other studies found no difference $[27,28]$. Our present findings are in agreement with the latter because the presence or absence of posts was not associated with the outcome of the treatment. The results from the present study confirmed previous findings regarding the quality of the root canal treatment as a key factor for prognosis. It was indicated that the tooth would still have a poor prognosis if the root canal filling was inadequate regardless of whether the coronal restoration was adequate, inadequate, or absent, when compared to an adequately filled tooth [28].

Tronstad et al. [3] suggested that a correlation exists between the quality of the restoration and periradicular health but concluded that the quality of the restoration was significantly less important than the quality of the root canal filling. Kirkevang et al. [23] stated that the combination of inadequate root canal treatment and inadequate coronal restoration was associated with an increased incidence of apical periodontitis, which is in line with our study.

Torabinejad et al. [29] suggested that direct exposure of a root canal filling to microorganisms and their products may facilitate reinfection of the root canal system in a relatively short time. Similarly, our results indicated that, when root canal treatment was inadequate, there was a $17.9 \%$ difference between the inadequate and adequate crown restoration groups associated with the occurrence of apical periodontitis. On the contrary, Ricucci and Bergenholtz [30] indicated that well-prepared and filled root canals resist bacterial penetration even upon frank and long-standing oral exposure by caries, fracture, or loss of restoration.

As this is a cross-sectional study, it provides information about a group of participants at one point in time. The data to be analyzed are restricted to available information and thereby are subject to bias of interpretation, which is one of the limitations of our study. Another limitation of our study is that no information was available about the time elapsed since endodontic treatment and many lesions might have decreased in size and still have been healing. Besides, apical periodontitis lesions which are limited to the cancellous bone might pass unnoticed in a radiographic examination, and without clinical data the radiographic evaluation did not always provide reliable information. Thus larger sample sizes with additional clinical data and examination should be performed for this kind of study. 


\section{Conclusion}

This study provided epidemiological data about apical periodontitis in a Turkish Cypriot population. Our findings showed a high prevalence of periapical pathology with or without endodontic treatment and poor technical standard of both root fillings and coronal restorations of root-treated teeth. Hence, we suggest the need for better education for dental health providers so that they can perform better root canal treatments and coronal restorations.

\section{References}

1 Dugas NN, Lawrence HP, Teplitsky PE, Pharoah MJ, Friedman S: Periapical health and treatment quality assessment of rootfilled teeth in two Canadian populations. Int Endod J 2003;36:181-192.

\2 Kirkevang LL, Ørstavik D, Hörsted-Bindslev P, Wenzel A: Periapical status and quality of root fillings and coronal restorations in a Danish population. Int Endod J 2000;33: 509-515.

-3 Tronstad L, Asbjørnsen K, Doving L, Pedersen I, Eriksen HM: Influence of coronal restorations on the periapical health of endodontically treated teeth. Endod Dent Traumatol 2000;16:218-221.

-4 Touré B, Kane AW, Sarr M, Ngom CT, Boucher Y: Prevalence and technical quality of root fillings in Dakar, Senegal. Int Endod J 2008;41:41-49.

5 Zitzmann NU, Krastl G, Hecker H, Walter C, Weiger R: Endodontics or implants? A review of decisive criteria and guidelines for single tooth restorations and full arch reconstructions. Int Endod J 2009;42:757-774.

6 Gencoglu N, Pekiner FN, Gumru B, Helvacioglu D: Periapical status and quality of root fillings and coronal restorations in an adult Turkish subpopulation. Eur J Dent 2010;4: $17-22$.

7 Lupi-Pegurier L, Bertrand MF, Muller-Bolla M, Rocca JP, Bolla M: Periapical status, prevalence and quality of endodontic treatment in an adult French population. Int Endod J 2002;35:690-697.

-8 Figdor D: Apical periodontitis: a very prevalent problem. Oral Surg Oral Med Oral Pathol Oral Radiol Endod 2002;94:651-652.

-9 Marques MD, Moreira B, Eriksen HM: Prevalence of apical periodontitis and results of endodontic treatment in an adult, Portuguese population. Int Endod J 1998;31:161165.

-10 De Moor RJ, Hommez GMG, De Boever JG, Delmé KI, Martens GE: Periapical health related to the quality of root canal treatment in a Belgian population. Int Endod J 2000;33: 113-120.
Buckley M, Spangberg LSW: The prevalence and technical quality of endodontic treatment in an American subpopulation. Oral Surg Oral Med Oral Pathol Oral Radiol Endod 1995;79:92-100.

12 Tsuneishi M, Yamamoto T, Yamanaka R, Tamaki N, Sakamoto T, Tsuji K, Watanabe T: Radiographic evaluation of periapical status and prevalence of endodontic treatment in an adult Japanese population. Oral Surg Oral Med Oral Pathol Oral Radiol Endod 2005; 100:631-635.

13 Al-Shammari KF, Al-Ansari JM, Al-Melh MA, Al-Khabbaz AK: Reasons for tooth extraction in Kuwait. Med Princ Pract 2006;15: 417-422.

14 Hessari H, Vehkalahti MM, Eghbal MJ, Murtomaa HT: Oral health among 35- to 44-year-old Iranians. Med Princ Pract 2007; 16:280-285.

15 Gündüz K, Avsever H, Orhan K, Demirkaya $\mathrm{K}$ : Cross-sectional evaluation of the periapical status as related to quality of root canal fillings and coronal restorations in a rural adult male population of Turkey. BMC Oral Health 2011;20:11-20.

16 Orstavik D, Kerekes K, Eriksen HM: The periapical index: a scoring system for radiographic assessment of apical periodontitis. Endod Dent Traumatol 1986;2:20-34.

17 Altman DG: Practical Statistics for Medical ${ }_{27}$ Farzaneh M, Abitbol S, Friedman S: TreatResearch: London, Chapman \& Hall, 1991.

18 Siqueira JF: Aetiology of the endodontic failure: why well-treated teeth can fail. Int Endod J 2001;34:1-10.

19 Boucher Y, Matossian L, Rilliard F, Machtou P: Radiographic evaluation of the prevalence and technical quality of root canal treatment in a French subpopulation. Int Endod J 2002; 35:229-238.

20 Muhammed AH, Manson-Hing LR, Ala B: A comparison of panoramic and intraoral radiographic surveys in evaluating a dental clinic population. Oral Surg Oral Med Oral Pathol 1982;54:108-117.
21 Molander B, Ahlqwist M, Gröndahl HG Hollender L: Comparison of panoramic and intraoral radiography for the diagnosis of caries and periapical pathology. Dentomaxillofac Radiol 1993;22:28-32.

22 Skudutyte-Rysstad R, Eriksen HM: Endodontic status amongst 35 -year-old Oslo citizens and changes over a 30 -year period. Int Endod J 2006;39:637-642.

23 Kirkevang LL, Hörsted-Bindslev P, Ørstavik D, Wenzel A: Frequency and distribution of endodontically treated teeth and apical periodontitis in an urban Danish population. Int Endod J 2001;34:198-205.

24 Siqueira JF Jr, Rôças IN, Alves FR, Campos LC: Periradicular status related to the quality of coronal restorations and root canal fillings in a Brazilian population. Oral Surg Oral Med Oral Pathol Oral Radiol Endod 2005;100:369-374.

25 Segura-Egea JJ, Jiménez-Pinzón A, PoyatoFerrera M, Velasco-Ortega E, Ríos-Santos JV: Periapical status and quality of root fillings and coronal restorations in an adult Spanish population. Int Endod J 2004;37: 525-530.

26 Loftus JJ, Keating AP, McCartan BE: Periapical status and quality of endodontic treatment in an adult Irish population. Int Endod J 2005;38:81-86. ment outcome in endodontics: the Toronto study - phases I and II: orthograde retreatment. J Endod 2004;30:627-633.

28 Siqueira JF Jr, Rôças IN, Debelian GJ, Carmo FL, Paiva SS, Alves FR, Rosado AS: Profiling of root canal bacterial communities associated with chronic apical periodontitis from Brazilian and Norwegian subjects. J Endod 2008;34:1457-1461.

29 Torabinejad M, Ung B, Kettering JD: In vitro bacterial penetration of coronally unsealed endodontically treated teeth. J Endod 1990; 16:566-569.

-30 Ricucci D, Bergenholtz G: Bacterial status in root-filled teeth exposed to the oral environment by loss of restoration and fracture or caries - a histobacteriological study of treated cases. Int Endod J 2003;36:787-802. 